\title{
CLOUD ACCOUNTING AND FINANCIAL REPORTING
}

\author{
Owolabi, S.A A $^{\mathrm{a}}$ Izang, J.U $\mathrm{U}^{\mathrm{b}}$ \\ aowolabis@babcock.edu.ng \\ bjuliaizang@gmail.com \\ ${ }^{a, b}$ Department of Accounting, School of Management Science, Babcock University, Ilishan-Remo, Ogun State, \\ Nigeria
}

\begin{abstract}
Cloud accounting is seen to lead to considerable increase in productivity because it helps accountants in small and medium business to provide quality financial reporting to their customers and arrangements on their money related issues and furthermore help accountants to exploit budgetary counsel and settle on better and fast choices, in this manner improving in general money related execution. In this work the effect of cloud accounting on financial reporting qualities of SMEs was evaluated. This work discovered that there is need for SMEs to adopt cloud accounting technology. This will increase their financial reporting quality and financial performance. The study recommends that the management should render their support on the adoption and smooth running of the cloud computing by providing the necessary resources needed and also for computer technologist to solve the security issues that comes with cloud accounting technology. The study hereby concludes that cloud accounting has a positive effect on financial reporting qualities of SMEs.
\end{abstract}

Keywords - Cloud accounting, Financial reporting, Financial reporting qualities, SMEs

\section{Introduction}

The need for delivering quality financial report has gotten extraordinary consideration over the world. Giving top notch financial reporting data is significant in light of the fact that it will emphatically impact capital suppliers and different partners in making speculation, credit and comparative asset designation choices improving by and large market effectiveness (IFRS, 2018). For corporate data to advantageous, IASB contends that a key essential quality in financial reporting is the adherence to the target and the subjective attributes of financial reporting (Al-Dmour, Abbod, \& Al Qadi, 2018).

The essential target of financial reporting is to give top notch financial information concerning financial elements, fundamentally budgetary in nature, helpful for financial dynamic (IFRS,2018). Giving top notch financial reporting information is significant in light of the fact that it will decidedly impact capital suppliers and different partners in making speculation, credit, and comparable asset allotment choices upgrading by and large market productivity (Ferdy, Geert and Suzanne, 2009).

Nigeria, there is additionally arrangement of all around pitched instances of accounting scandal. The condition of financial reporting oversight gave by corporate review boards of trustees is a wellspring of worry to the Securities and Exchange Commission (SEC). The fiscal reports fill in as the essential apparatus for the executives to convey financial and operational information as the board responsibility and to address the issues of interior and outside gatherings who do not have the power to get the necessary information from the immediate wellsprings of the organization (Schipper and Vincent, 2003). As expressed in the essential system for the readiness and introduction of budget summaries that the motivation behind fiscal reports is to give data identifying with the financial position, execution, and changes in the financial situation of an element that is beneficial to countless clients in financial dynamic (Usdi, 2018).

The nature of financial reporting depends, and relies on, the benefit of accounting information. Over the world, the interest has gone out for giving a reasonable and full meaning of financial reporting quality. It is basic to give excellent financial reporting information to impact clients in settling on speculations choices and to improve advertise effectiveness. Giving perfect techniques to evaluating the nature of financial information is another worldwide interest. The higher the nature of financial reporting, the more noteworthy are the advantages to be picked up by speculators and clients of the financial reports. In addition, financial reporting quality is a wide idea that doesn't simply allude to financial information; it likewise incorporates other non-financial related information that is helpful for deciding (Siriyama and Norah, 2017). 
Accounting has advanced reliably over the previous decades, with each new expansion and development making it shockingly better and testing while at the same time giving fulfillment and accommodation to the clients. Current accounting has arrived at the current stage in the wake of experiencing slow changes throughout the years; by staying up with the quick developing innovative headways. There has been predictable adjustment and improvement from manual techniques to mechanical options which has made accounting simpler and helpful for clients. The ongoing movement in accounting towards quicker innovations has hugely expanded its ability to serve clients (Rao, Jyotsna and Sivani, 2018). Cloud Accounting is relied upon to make accounting effectively available, more affordable and efficient. Cloud Accounting includes utilization of cloud-based programming through any gadget having web association (Rao et al, 2018).

The need for Small and medium scale undertakings (SMEs) to enter into this recent trend in technology and receive appropriate developments that will assist with improving the nature of their finance report and furthermore assess factors influencing innovative selections is the main idea this paper solved.

\section{Statement of the Problem}

Financial reporting requires the arrangement of accounting related information by the administration to address the issues of different clients. The Financial Accounting Standards Board (FASB, 2006) indicated financial divulgence should make accessible actuality that remaining parts noteworthy for settling on normal choices by speculators, loan bosses and different clients (Moses, Ofurum and Egbe, 2016) It is normal that the financial reports ought to be a proper record of business exchanges that presents an across the board clarification of the situation in the short and since quite a while ago run of a firm to the individuals who utilize these fiscal reports (Igben, 1999).

Lately, powerless inside control and fake exercises among others that are obvious inside organizations has prompted a temperamental accounting related detailing proclamation to its clients. Accounting information quality in Nigeria stays powerless contrasted with many propelled locales. This brought about hampering of the development of effective value markets. A typical grievance among speculators in Nigeria is that financial information on organization execution is either inaccessible or, whenever gave, needs dependability (Shehu, 2011). The Nigerian settings as far as accounting announcing characteristics, structure, and corporate administration are relied upon to appear as something else and better as far as headway and consistence (Shehu and Ahmad, 2013).

Passed studies carried out have recommended cloud accounting has one of the ways for curbing such irregularities in the accounting system. These trending technologies are being used by large scale enterprises. This study seeks to investigate cloud accounting and financial reporting qualities of small and medium scale enterprises (SMEs) in Nigeria.

\section{Literature Review}

The budget summary of any firm is relied upon to have the necessary subjective qualities as expressed by International Financial Reporting Standards which incorporate importance, equivalence, practicality, understandability, unwavering portrayal and undeniable nature. The fiscal report ought to consistently portray itemized data about the financial presentation of a firm (as featured in the pay proclamation), the announcement of money related position, articulation of incomes and explanation of changes in value (IAS 1). This is to guarantee that the data gave is of top notch (Aifuwa and Embele, 2019).

Money related detailing is the arrangement of budgetary data about an element to outer clients that is important to them in settling on financial choices and for evaluating the viability of the element's administration. Budget summaries pass on both subjective and quantitative data to help clients in settling on an educated financial choice. Dependable and excellent fiscal reports that are liberated from any material errors or deception improve clients' choice - making quality (Oji and Ofoegbu, 2017).

The goal of monetary revealing is to give data about the detailing element that is valuable to existing and possible financial specialists, moneylenders and different loan bosses in settling on choices about giving assets to the substance. Money related reports give data about the budgetary situation of a revealing substance, which is data about the element's financial assets and the cases against the announcing element. Budgetary reports likewise give data about the impacts of exchanges and different occasions that change an announcing element's financial assets and cases. 
Cloud computing rose around 2007, is quickly being received by associations, including little and medium ventures (SMEs), in different segments. Customarily, associations have been actualizing applications utilizing programming that should be introduced on at least one physical servers. In a cloud computing condition, the association running an application doesn't ordinarily claim the physical equipment utilized for the applications and doesn't typically have the foggiest idea where the calculation work of the applications is being prepared. Cloud computing has been utilized by a huge number of individuals in different signs, including free email administrations (e.g., Yahoo Mail and Gmail) and free office efficiency applications (e.g., Google Apps). The innovation offers associations its one of a kind highlights, including high accessibility, versatile adaptability, less intricacy, speed, nimbleness, adaptability, and monetary bit of leeway. In spite of its significance, restricted examination has anyway contemplated the reception of distributed computing in SMEs (Hassan, 2017).

Cloud accounting programming uses the Cloud to store accounting information. It makes accounting related data available to proprietors and workers any place with an Internet association. Consistently, an ever increasing number of organizations are going to distributed computing. From associated machines to Internet-based training programs, individuals everywhere throughout the world are using the cloud as a method of interfacing with clients and making their own strategic policies progressively compelling. One business practice than an expanding number of organizations are going to Internet-based innovation for is bookkeeping. Today, independent companies over the globe are exploiting the cloud with regards to dealing with their funds and less and less new companies currently rely upon a hard drive to store and access their bookkeeping information (Tahmina, 2017).

Cloud Accounting Software was mostly evolved to take care of the issue of transportability of information. Prior, a document required to be gotten to later was put away on hard drives or USB streak drives. Gadgets like Hard drives, USB streak drives and other compact stockpiling gadgets made shipping data between different machines a simple procedure. Nonetheless, these conventional strategies for capacity had critical disadvantages. For instance, information put away on hard drives are vulnerable to loss of information through various circumstances, for example, fire mishaps, non-working of any of the small mechanical pieces of the drive, and so on. In the event that a significant archive is put away on a USB streak drive there is consistently an opportunity of losing the information during venture out or because of harm happening to the drive. The working of Cloud based bookkeeping programming is like the other cloud based programming. Records which are by and large put away on a hard drive are put away on the web. This guarantees the data is effectively available (Rao, Jyotsna and Sivani, 2018).

\section{THEORETICAL FRAMEWORK}

\section{A. System theory}

System theory expresses that organizations ought to be treated as an open framework that changes contributions to yields inside the conditions (outside and interior) whereupon they are reliant (Miller and Rice 1967). System theory is the premise of the info procedure yield result model of overseeing execution, which evaluates the whole commitment that an individual makes inside the framework in doing their assigned activities, not simply the yields. Data sources contain the skills and information that an individual brings to a vocation. Aptitudes and information are estimated to survey improvement and adapting needs of workers. Results measure the size of the person's commitment to in general group, division and corporate execution, and are integral to execution the board. This strategy for overseeing execution is significant in light of the fact that all the variables that impact execution, including the framework and the unique situation, can be considered while evaluating it (Miller and Rice 1967).

Ludwing Von Bertalanffy (1973) perceived the need of any organization to communicate with its outer environment, not at all like what was proposed by old style school scholars like Max Weber, F. Tailor and Fayol who saw association as shut framework. To him, for endurance of an association like the manner in which living being endures, ought to work in open framework and not shut framework. This is the thing that caused his work to make framework ideas to get perceived worldwide as way to deal with be adjusted by organization for their productivity and viability in the dynamic and evolving conditions. He was against reductionism, contending that, genuine framework are open and do collaborate with outside condition, where he underscored on comprehensive quality while tackling association issues. Along these lines, open framework changed the perspective about hierarchical administration from mechanical perspective on association. It takes a gander at the executives as an open-finished procedure. It stressed separation, objectivity and control. Today organization are seen as an open finished procedure of planning intentional people whose activities come from applying their one of a kind translations to the specific circumstances standing up to them. For example, in current circumstance, an association which won't be touchy to its condition will scarcely endure. Things like innovation, social and financial wonders are not static but rather are continually changing, henceforth associations are expected to receive so as to endure (Chikere and Nwoka, 2015) 
This theory is adopted in this work because organization relies upon the globe for its data sources, yet for the acknowledgment of yields. Thusly, they should create implies for adapting to natural requests. Basically, there is no way a company will survive without its interaction with its internal and external environment especially when it comes to adopting new technologies like cloud accounting.

\section{EMPIRICAL REVIEW}

Mugyenyi (2018) explored on the reception of Cloud Computing Services by Commercial Banks in Uganda for Sustainable Development. The investigation found that business banks in Uganda are consistently expanding in number of branches, sizes and operational exercises over the most recent two decades. This augmentation has pulled in high operational costs identified with buy and upkeep of IT framework and in any event, requiring bigger spaces to oblige them, which is constantly joined by helpless information stockpiling and the board. Cloud computing proffer the best and most recent answer for check the issues distinguished in the business banks, as featured in this examination if and when embraced.

Haslinda, Mohd and, Norhaiza (2017) researched Cloud Computing Adoption in Organizations. The examination survey writing on distributed computing appropriation in associations to distinguish its compelling components and its operationalisation in earlier writing. The scientists arrange the variables that impact the distributed computing reception utilizing the three settings recommended by the Technology Organization-Environment (TOE) system, to be specific, innovation, association, and condition. The finding from the examination recommends that the impacts of these elements differ across studies and a large portion of the investigations have operationalised distributed computing appropriation utilizing aim to embrace distributed computing or double factor, as opposed to the real utilization of the innovation.

Tahmina (2017) did a hypothetical audit of cloud bookkeeping. The examination shows that the development of bookkeeping programming utilizing the cloud innovation has improved the act of bookkeeping altogether, which is one of the enormous IT advancements in the course of the most recent decade. Like different divisions of business, bookkeeping has likewise grasped distributed computing arrangements so as to give important and specific data just as a constant review of business for all partners. Despite the fact that cloud bookkeeping is turning out to be increasingly more typical step by step, numerous entrepreneurs and experts are not exactly secure with what it is, the thing that its advantages are or how it will shape the future bookkeeping. The examination finished up by giving a hypothetical review of cloud bookkeeping covering its idea, benefits, weaknesses, correlation with the conventional one and some other significant angles that may shape the bookkeeping calling in the coming years.

Perri and Muça (2015) completed an investigation on the job of distributed computing in bookkeeping enterprises in Albania. The investigation sees distributed computing as an innovation dependent on the web which encourages the administration and conveyance of registering administrations through the system is by all accounts the perfect reaction that addresses issues of bookkeeping firms as far as gathering, putting away, handling and detailing data. The specialists feature the impacts of this innovation in bookkeeping data frameworks and monetary execution having in center organizations that work in Albania. The examination discover that despite the fact that the degree of data about distributed computing is impressive, the wellsprings of data are not as much from business foundation but instead from scholarly sources and individual investigations. Besides the examination found that the best advantages of distributed computing innovation are seen to be cost reserve funds both in equipment and programming, while data security and unwavering quality are referenced as its greatest downsides.

Okoye and Akenbor (2014) examined the monetary detailing system in Nigeria and the appropriation of the worldwide money related announcing principles. In this investigation a hypothetical assessment of the structure of money related detailing in Nigeria opposite the appropriation of the International Financial Reporting Standards (IFRS) was introduced. The investigation did a broad survey of writing, uncovered the issues, advantages and difficulties in the progress from Generally Accepted Accounting Principles (GAAP) to IFRS. The examination toward the end suggested that corporate elements in Nigeria ought to adjust to the International Financial Reporting Standards instead of complete selection of the measures and to guarantee its maintainability, a nationwide serious limit building program is a "sine qua non". 
Strauss, Kristandl and Quinn (2014) completed an examination on the impacts of cloud innovation on the executives bookkeeping and dynamic. The examination shows that administration bookkeeping and account frameworks are most drastically averse to be cloud-situated in inclination to different frameworks, regardless of a valuation for the upsides of cloud innovation when all is said in done. While the purposes behind this might be legitimate (information security), the feasible cost reserve funds and frameworks adaptability should be deliberately thought of. The executives accountants can assume a job in not just assessing expenses and advantages of cloud innovation, yet in addition in guaranteeing that the benefits of progressively cooperative business forms are imparted to supervisors and acknowledged by any usage of cloud innovation. Second, the board accountants are very much positioned to work with specialized specialists and additionally cloud specialist organizations to guarantee information security issues are appropriately tended to. The analysts anticipate that its utilization should develop after some time, and further examination on how the innovation will influence the arrangement of dynamic data and the job of the administration bookkeeper would be welcome and smart.

Al-zoubi (2017) examined on the Effect of Cloud Computing on Elements of Accounting Information System, The examination recognizes the effect of Cloud Computing on the Elements of the Accounting Information System spoke to by: Establishment "Bookkeeping Entity.", Financial Operations, Documents, Accounting Books, Financial Reporting, Users, Procedures, Software, and Physical Devices. The examination gathered past writing on distributed computing and data innovation and studies their effect on bookkeeping data frameworks. The examination discovered that Cloud Computing lead to Reducing the size of the venture as far as the structure and the workplaces since they permit property anyplace without the executives responsibility to a particular area, Improving operational execution as far as encouraging the finishing of activities and exact bookkeeping tasks, The cloud has become a spot for the fulfillment of tasks and exchange between representatives or clients with big business framework, Dispensing the reports to guarantee they are self-administration to clients, decrease the quantity of sales reps since it empowers clients to look at the set up items and offer deals arranges electronically from an assortment of topographical areas without the need to assign deals to go among customers lastly distributed computing gives a product as an assistance stage were people and firms can utilize programming and physical hardware without the need to purchase the product and introduce it on their PCs.

Gupta and Gaur (2018) did an examination on the effects of distributed computing on bookkeeping. Distributed computing developed as the wellspring of change in the field of bookkeeping the same number of firms and people are driving towards the innovation for recording and understanding instead of depending on traditionalist techniques for bookkeeping. This examination endeavors to impact of distributed computing on bookkeeping in current situation. It likewise plots the advantages and difficulties looked by it and extension for its future development. This investigation utilized auxiliary information, to seriously apply individual information and thinking so as to drive ends. It was anyway seen that distributed computing is beating the time because of its cost viability and adaptability while hesitation on its adjustment is given due to its security issues and absence of help from partners. It is reasoned that human intercession is vital piece of distributed computing as dealing with cloud is finished by them, thus people who are doing bookkeeping utilizing ordinary strategies normally oppose the development of distributed computing because of their absence of enthusiasm for tolerating this change and they are not steady enough to learn new innovation.

Gilaninia, Chegini and Mohtasham(2013) completed an examination on the significance of Financial Reporting and factors influencing it, Financial announcing purposes come from data needs and requests of outside the association clients. The primary objective is monetary impacts of occasions and money related procedure on the status and execution of the specialty unit for help to outside elements and budgetary dynamic regarding the specialty unit. The examination explored the connection between the nature of monetary announcing and venture proficiency. Anticipated higher caliber of budgetary announcing, improves speculation execution by diminishing data asymmetries between specialty unit and outside providers. Nature of money related detailing can improve speculation productivity from two different ways: First, through diminishing data asymmetries among organization and speculators, in this way decrease monetary expenses. Second, through diminishing data asymmetries among financial specialists and administrators accordingly decrease observing expenses and improving venture choice.

Dimitriua, and Mateia (2014) explored on distributed computing as another worldview for Accounting, the effect of globalization, the fast advances in science and innovation, the ascent of huge information, the wide spread of web based applications and even normalization have made the correct setting for the development of another idea - cloud bookkeeping. The digitization of business, the expanding plentifulness of augmented reality, the transformation of 
customary PC business plans towards cloud-based arrangements are hidden drivers of progress that shape the genuine standards of the market. Then again, bookkeeping is a basic segment of the system that continues any venture's movement. The focal point of this examination was on the effect of the distributed computing worldview on the bookkeeping area. The methodology in this investigation is explicitly focused on the money related ramifications and the valuing contributions that join distributed computing. Moreover, the investigation breaks down the key angles that ought to be considered by any organization when choosing to pick the correct bookkeeping framework.

\section{METHODOLOGY}

This study was carried out to evaluate cloud computing and financial reporting qualities of SMEs. The study made use of a singular source of data. Secondary sources of data generation were employed through the use of published journals, articles and gazette. The data was examined by reviewing various data from related areas to the study and all variable in the study was reviewed

\section{DISCUSSION OF FINDINGS}

Past research has shown that cloud computing is beneficial to business entities. It helps to increase the quality of financial reports because it is presented in a more organized way with sophisticated cloud accounting software. According to Gupta and Guar (2018) the benefit of Cloud Accounting is that it works same as accounting works however utilizing web. Cloud supplier gives the online server from where any client, organization or association can get to their information through web. As of now cloud bookkeeping is beginning from enlightening society which is prepared to change itself from utilizing customary strategy for information dealing with and capacity to electronic data arrangements. Solicitations can be filtered immediately and scattered to the bookkeeping framework consequently after which checking and affirming the section should be possible by bookkeeper. It prompts cost sparing in preparing as the checking of solicitations should be possible in mass by customer themselves. So as to evaluate their business execution, they simply need to sign into the bookkeeping association's entrance. The data of money vacillation's effect or following of income should be possible which is useful in creating confidence in business choices of customers. Different administrations like business investigation or income determining can be rendered by bookkeepers to offer a top to bottom budgetary mastery which is fundamental to guarantee development of business.

Further, Cloud-based bookkeeping frameworks give the devices to destroy dangers of error and irregularity of information that frameworks worked by ancestor made. It likewise assists with making reviews and authentic following helpful, most cloud based stages structure a review trail as part of their general record. This use of cloud accounting can help small and medium scale organization capture their transactions appropriately and accurately however it has some disadvantages which must be looked into for Future development and upgrading. According to Tahmina, (2017), Gupta and Guar (2018) and Rao, Jyotsna \& Sivani, (2018). Some of the disadvantages of using cloud accounting is the lack of security of financial data in the cloud. Professional hackers can break into vital information of companies in the cloud thereby manipulating and compromising such information. Financial information is the most sensitive information in an organization which needs to be protected by all means. Saving information in the cloud could lead to high cost of maintenance which SMEs might not be able to afford. Business entities should be introduced to cloud based accounting systems that suits their purpose and it should be affordable at the same time.

\section{CONCLUSION}

The quick development of distributed computing has gotten a prevailing noteworthy in creating nations; a great deal of firms are searching for advanced method of completing their activities. Distributed computing innovation (Cloud accounting) has brought putting away and overseeing information on virtualized servers so that, applications, people and associations around the globe can be able to interface with information and registering assets anyplace and whenever. This thought of putting away information or running applications on mists has been demonstrated effective in improving the unwavering quality in money related revealing since the information and application are stockpiled sponsored up in the cloud which diminishes the opportunity of information and application misfortune. Cloud accounting has been believed to be valuable to both little and medium scale undertakings in Nigeria for the most part as a result of the enormous number of SMEs in the nation. 


\section{Recommendations}

There is need for the management of an organization to improve the quality of financial reporting through cloud accounting. Cloud accounting is a very important tool which aids the credibility of the financial state and also helps in increasing the performance of SMEs. Those charged with governance should render their supports in the process of adopting cloud computing

The policy makers should adjust certain policies that are unfavorable and abolish outdated policy. most times policies adopted are not favorable SMEs. The policy makers should review policies related to subsidies that will enable SMEs grow their businesses and adopt cloud accounting technologies. The policy makers should be able to understand the economic situation and profer appropriate solutions to achieve a growing economy.

The government should provide funds through loan facilities, incentives schemes and subsidies on products. This will help SMEs to generate revenue that will help them adopt emerging technologies which will lead to economic development on the long run. The government should understand the need for small businesses to grow and also make regulations that are favorable to SMEs.

Computer technologist should carry out more studies on emerging technologies and innovations, find lasting solutions to cloud security issues and ways to make adoptions and the transition period for SMEs smooth.

\section{References}

Adeyemi, S.B., \& Johnson, K.O., (2011) Stakeholders' Perception of Audit Performance Gap In Nigeria, International Journal of Accounting and Financial Reporting, 1(1), 152-172, ISSN $2162-3082 \quad 2011, \quad$ DOI: 10.5296/ijafr.v1i1.808.

Aifuwa, H.O., \& Kemebradikemor Embele, K. (2019) Board Characteristics and Financial Reporting Quality, Journal of Accounting and Financial Management, 5(1), 30-49, ISSN 2504-8856, available at www.iiardpub.org

Al-Dmour, A.H., Abbod, M., and Al Qadi, N.S. (2018) The Impact Of The Quality Of Financial Reporting On Non Financial Business Performance And The Role Of Organizations Demographic' Attributes (Type, Size And Experience), Academy of Accounting and Financial Studies Journal, 22(1), 1-18.

Al-zoubi, A,M. (2017) The Effect of Cloud Computing on Elements of Accounting Information System, Global Journal of Management and Business Research Accounting and Auditing, 17(3), 1-8.

Dimitriua, O., \& Mateia, M. (2014) A New Paradigm for Accounting through Cloud Computing, Procedia Economics and Finance, 15(2014), 840 - 846, Available online at www.sciencedirect.com, Published by Elsevier

Ferdy, V.B., Geert, B., and Suzanne, B. (2009) Quality of Financial Reporting: measuring qualitative characteristics, Nijmegen Center for Economics (NiCE), Institute for Management Research, Radboud University Nijmegen

Financial Accounting Standards Board. (2006,). Preliminary Views on an improved Conceptual Framework for Financial Reporting: The Objective of Financial Reporting and Qualitative Characteristics of Decision-useful Financial Reporting Information. http://www.fasb.org/cs/BlobServer?blobcol=urldata\&blobtable=MungoBlobs\&blob key=id\&blobwhere $=1175818764152 \&$ blobheader=application\%2Fpdf $(15.07 .2011)$

Gilaninia, S., Chegini, M.G., \& Mohtasham, E.M. (2013) The Importance of Financial Reporting and Affecting Factors on It, Arabian Journal of Business and Management Review (Nigerian Chapter), 1(10), 70-78.

Gupta, A.K., \& Gaur, P. (2018) Impacts of Cloud Computing on Accounting: Aids, Challenges And Its Future Growth, EPRA International Journal of Economic and Business Review, 6(3) 49-54

Haslinda, H., Mohd, H.M.N., and Norhaiza, K. (2017) Cloud Computing Adoption in Organisations: Review of Empirical Literature, SHS Web of Conferences 34, 02001

Hassan, H. (2017) Organisational factors affecting cloud computing adoption in small and medium enterprises (SMEs) in service sector, CENTERIS - International Conference on Enterprise Information Systems / ProjMAN - International Conference on Project management / HCist International Conference on Health and Social Care Information Systems and Technologies, ENTERIS / ProjMAN / HCist 2017, 8-10 November 2017, Barcelona, Spain. Science Direct Procedia Computer Science 121 (2017) 976-981, Available online at www.sciencedirect.com 
IFRS Foundation (2018) Conceptual Framework for Financial Reporting, Status and Purpose of the conceptual framework, International Accounting Standards (IAS), 'International Financial Reporting Standards (IFRS).

Igben (1999). In Adebayo, O. (2011). "An Empirical Analysis of the Impact of Auditor Independence on the Credibility of Financial Statements in Nigeria: Research Journal of Finance and Accounting 2 (3). 82 -98.

Mahdi, S., (2010) Evaluating Effectiveness of External Auditors' Report: Empirical Evidence from Iran, Pak. J. Commer. Soc. Sci. 2010 Vol. 4 (1), 69-83

Moses, T., C. O. Ofurum, and Egbe, S. (2016) Audit Committee Characteristics and Quality Of Financial Reporting In Quoted Nigerian Banks, International Journal of Advanced Academic Research, Social \& Management Sciences, 2(5), 1-10, ISSN: 2488-9849

Mugyenyi, R. (2018) Adoption of Cloud Computing Services for Sustainable Development of Commercial Banks in Uganda, Global Journal of Computer Science and Technology: B Cloud and Distributed, 18(1), 1-9. ISSN: 0975-4172.

Namazi, M., (2013) Role of the agency theory in implementing management's control, Journal of Accounting and Taxation, 5(2), 38-47, ISSN 2141-6664, DOI: 10.5897/JAT11.032

Oji, O., and Ofoegbu, G.N. (2017) Effect of Audit Committee Qualities on Financial Reporting of Listed Companies in Nigeria: A Perspective Study, International Journal of Scientific and Research Publications, 7 (10), 278 290, ISSN 2250-3153.

Okoye, P.V., \& Akenbor, C.O. (2014) Financial reporting framework in Nigeria and the adoption of the international financial reporting standards, International Journal of Business and Economic Development, 2(1), 52-63.

Perri, R.S., \& Muça, E. (2015) An Analysis Of Cloud Computing And Its Role In Accounting Industry In Albania, JISOM, 1(14), 1-12

Rao, M.T., Jyotsna, T.G., Sivani, T.G. (2018) Impact of Cloud Accounting: Accounting Professional's Perspective, IOSR Journal of Business and Management (IOSR JBM) ISSN: 2278-487X, p-ISSN: 2319-7668 PP 53-59

Shehu ,U. H., \& Ahmad, B. (2013) Firm Characteristics And Financial Reporting Quality Of Listed Manufacturing Firms In Nigeria, International Journal of Accounting, Banking and Management, 1(6), 47 - 63

Siriyama, K. H., Norah Albarqi. (2017) Financial Reporting Quality: A Literature Review, International Journal of Business Management and Commerce, 2(2), 1-14

Strauss, E., Kristandl, G., \& Quinn, M. (2014) The effects of cloud technology on management accounting and decision making, Chattered Institute of Management Accounting (CIMA), 10(6), 1-12

Tahmina, K. (2017) Cloud Accounting: A Theoretical Overview, IOSR Journal of Business and Management (IOSR JBM) e-ISSN: 2278-487X, ISSN: 2319-7668. 19 (6), 31-38, www.iosrjournals.org

Usdi, S. (2018) The Role of the Internal Audits to the Quality of Financial Reporting, Reports on Economics and Finance, 4(1), 1 - 14 HIKARI Ltd, www.m-hikari.com https://doi.org/10.12988/ref.2018.811 